\title{
Sir Roger Bannister (1929-2018) and his lifetime contributions to autonomic medicine
}

\author{
Christopher J. Mathias ${ }^{1,2,3}$
}

Received: 17 July 2018 / Accepted: 23 July 2018 / Published online: 20 August 2018

๑) Springer-Verlag GmbH Germany, part of Springer Nature 2018

Keywords Autonomic disorders · Orthostatic hypotension · Multiple system atrophy $\cdot$ Pure autonomic failure $\cdot$ Olympics · Physiology · Obituary

Sir Roger Gilbert Bannister was born on March 23, 1929. He led an exceptionally full life. He excelled in sport (he was the world's first sub-4-minute miler), in medicine (neurology and autonomic disorders), and in leadership (he was Chairman of the Sports Council and Master of Pembroke College at Oxford University). He was devoted to his family and close to his friends. He passed away peacefully on March 3, 2018, when we lost a colossal figure in autonomic medicine, a discipline that only became established in the clinical and academic firmament during his lifetime. The focus of this obituary will be his pioneering work and achievements in autonomic medicine. His many other personal and athletic accomplishments have been described elsewhere [1,2].

Sir Roger and I first met at Christchurch College, Oxford in 1976. He was the external examiner for my viva voce examination to defend my $\mathrm{PhD}$ thesis on cardiovascular autonomic disturbances in spinal cord injury. Sir Roger was most courteous but skilfully probing in his questions. The details are a blur, presumably because of my euphoria that the examiners endorsed my doctorate in philosophy. I had no inkling that a few years later we would work together, and that he would become a pivotal figure in my life, as he was to many in the autonomic field for the next four decades.

Sir Roger won a scholarship to Exeter College, Oxford in 1947 at the age of 17. After his degree, he became a Harmsworth Senior Scholar at Merton College and demonstrator

Christopher J. Mathias

profmathiasautonomic@gmail.com

1 Institute of Neurology, University College London, London, UK

2 Lindo Wing, St Mary's Hospital Imperial College Healthcare NHS Trust, London, UK

3 Autonomic and Neurovascular Medicine Centre, Hospital of St John and St Elizabeth, London, UK at the Oxford University Laboratory of Physiology from 1950 to 1952 . With Daniel Cunningham, he analysed respiratory responses to exercise in athletes and non-athletes with publications in the Journal of Physiology [3, 4]. During this period, he visited the Spinal Injuries Centre at Stoke Mandeville, where the Oxford physiologists had been collaborating with Sir Ludwig Guttmann on cardiovascular and sudomotor control in spinal injuries. This likely was the incipient stimulus for his lifelong interest in the autonomic nervous system.

In 1952 he won a scholarship to study medicine at St Mary's Hospital Medical School. He obtained his medical degree in 1954, soon after he broke the 4-minute mile barrier after which he retired from athletics. His postmedical graduation clinical experience included being house physician to Professor Sir George Pickering at St Mary's Hospital, whose expertise included the circulation and hypertension. From 1957 to 1959 he completed his military national service at Millbank and Aden as a Junior Medical Specialist, and later was Captain in the Royal Army Medical Corps. His astute observations and investigation of unacclimatized troops with hyperpyrexia led to his description of acute anhidrotic heat exhaustion, published in The Lancet in 1959 [5]. He went on to describe the possible effects of pyrogens, and the prevention and treatment of hyperpyrexia, a frequently fatal condition. This was the basis of his doctorate in medicine thesis on Temperature homeostasis and heat illness. His later clinical and allied training included working with Derek Denny-Browne in Boston as a research fellow at Harvard University in 1962.

In 1963, aged 33, he was appointed consultant physician at the National Hospital for Nervous Diseases, Queen Square, London, followed by a consultant neurology appointment at St Mary's Hospital a year later. Each of these appointments was busy and demanding clinically, 
given that they were at different institutions in separate locations. He additionally chose to focus on what was then a rare disorder, orthostatic hypotension due to autonomic failure. He evaluated these patients in detail, clinically and with physiological testing, collaborating with David Greenfield (Professor of Physiology at St Mary's), Peter Fenton and Leslie Ardill, with publications on the defective physiology of the blood vessels of those patients and on treatment strategies $[6,7]$. Of particular importance were his observations with the Oxford neuropathologist David Oppenheimer, that linked the clinical features of autonomic failure and cell loss in the intermediolateral column of the spinal cord with neuroanatomical changes in different regions of the brain (striatonigral and olivopontocerebellar atrophy) [8]. These findings would eventually support the renaming of Shy-Drager syndrome to its current nomenclature, multiple system atrophy.

Sir Roger understood the importance of sport for health, and promoted this nationally. He became the first Chairman of the British Sports Council from 1971 to 1974, and was knighted by HM Queen Elizabeth II in 1975 for services to sport. Under his direction funding for sports facilities at the local and central level was significantly increased, and he also championed the first tests for anabolic steroid detection in athletes.

In 1975 he founded the Autonomic Investigation Unit at Queen Square for the evaluation of patients with orthostatic hypotension and autonomic disorders. He was aided by his technical assistant Elizabeth Holly. He collaborated with Peter Sever and Bleddyn Davies in the Medical Unit at St Mary's Hospital Medical School, using refined techniques for the measurement of plasma noradrenaline and adrenaline levels to further define the neuroendocrine basis of autonomic failure and the abnormal cardiovascular responsiveness to various drugs in such patients [9-11].

In 1979 a combination of events resulted in us working together. After completing my postdoctoral clinical training, I considered my future. As various mentors pointed out, a lifetime career in autonomic medicine was a pipe dream. The brief elation of successful research and its clinical translation did not equate to reality, as the specialty was nonexistent, and patients with autonomic disorders were considered rare and usually were not recognised. Fortunately, from 1973 I had been collaborating with Professor Sir Stanley Peart at St Mary's Hospital Medical School on the sympathetic nervous system control of renin and aldosterone release in patients with spinal cord injury. He suggested I join him in the Medical Unit he directed, to study the neurogenic (autonomic) basis of essential hypertension, which was one of his major interests. The Wellcome Trust enabled me to join his department in 1979 with a senior clinical research fellowship. Sir Roger was also at St Mary's Hospital, and our collaborations began, also at Queen Square in 1981. The autonomic field in the 1980s was still in its infancy, although this was changing rapidly. Sir Roger's drive and the critical mass of those working in the autonomic field in London resulted in the hospitals becoming the epicentre for the referral of patients with orthostatic hypotension and autonomic disorders. In 1984, the Wellcome Trust again enabled me, as Senior Lecturer in Medicine, to work alongside Sir Roger and Sir Stanley.

As more patients with autonomic failure were studied, it emerged that there were clinical subtypes which differed substantially in their clinical course and prognosis. A group of patients, referred to as pure autonomic failure, had isolated autonomic failure with no other neurological deficits. In contrast, a second group had autonomic failure in combination with parkinsonian or cerebellar features, at that time referred to as the Shy-Drager syndrome. Advances were made in separating the two at an early stage based on differences in plasma catecholamine levels and the growth hormone response to the centrally acting adrenergic agonist clonidine [12]. It also became evident that key stimuli in daily life other than postural change could exacerbate orthostatic hypotension in such patients. This lead to a series of studies on early-morning, postprandial and exercise-induced hypotension [13-15].

Observations of exceptionally rare conditions can result in new areas of research and therapy. An unusual case was a 20-year-old man with severe orthostatic hypotension who, unlike others with autonomic failure, had undetectable plasma noradrenaline and adrenaline but extremely high dopamine levels. His sister had similar features. A series of studies began on the only two siblings in the world diagnosed with dopamine beta-hydroxylase deficiency. The oral noradrenaline synthetic precursor agent L-dihydroxyphenylserine (L-DOPS, droxidopa) was obtained from Japan, where it originally was used to treat orthostatic hypotension in patients with amyloidosis and to reduce gait abnormalities in Parkinson disease. Droxidopa increased plasma noradrenaline levels towards normal and has had a remarkable effect on the siblings, allowing them to lead full lives since they first started on the drug in 1986 [16]. Their beneficial response to droxidopa was one of the stimuli for multicentre trials in patients with neurogenic orthostatic hypotension [17], which eventually resulted in its approval by the US Food and Drug Administration in 2014 to treat symptomatic neurogenic orthostatic hypotension.

Sir Roger was a key figure in advancing the autonomic field internationally. The Clinical Autonomic Research Society was founded in 1982 and he was its first chairman, with Peter Watkins (a diabetologist at King's College) as treasurer and myself as secretary. The initially small meetings grew steadily over the decade with considerable input from colleagues in Europe (Wouter Wieling in Amsterdam and Pietro Cortelli in Bologna, amongst others) and the United 
States (Ron Polinsky at the National Institutes of Health, Bethesda). In the late 80s and 90s, these grew steadily and became international meetings. His editorial skills were much lauded, as with the multiple editions of Brain and Bannister's Clinical Neurology. In 1983, he published Autonomic Failure, the first textbook of clinical disorders of the autonomic nervous system. In the first edition, there were 29 chapters covering basic and clinical autonomic medicine, written by 31 authors. Its success led to four further editions, the fifth edition published in 2013 [18] with 72 chapters and 112 contributors, reflecting the many global advances in the autonomic field over this period.

In the mid-1980s, it was felt that a journal focusing on the autonomic nervous system was much needed. This was a daunting task in what was then a small field. With the support of Ivan Klimes and Rapid Communications of Oxford, the journal Clinical Autonomic Research was created, with the first issue published in March 1991. Since then, the journal has grown steadily to become the benchmark journal on autonomic medicine. Sir Roger remained as Chairman of the Editorial Board since it was founded in 1991. The arrival of Clinical Autonomic Research strengthened global ties in the autonomic field. In 1992, the American Autonomic Society (AAS) was formally established by leading academics (Ron Polinsky, David Robertson, David Streeten and Phillip Low, amongst others). The European Federation of Autonomic Societies (EFAS) was founded in 1999. Clinical Autonomic Research became the official journal of the AAS and EFAS. The first joint AAS/EFAS meeting was held in Amsterdam in 2004 and the highlight was the Sir Roger Bannister
Lecture in tribute to him, that in his usual modest manner he was justifiably proud of. In 2005, he was presented with the first Lifetime Achievement Award by the American Academy of Neurology, in recognition of his contribution to the understanding of autonomic problems in various diseases.

Sir Roger was a true polymath, dedicated to his various commitments despite a punishing workload (Fig. 1). He became Master at Pembroke College in Oxford in 1985, and until 1989 he continued his clinical and research activities in London, spending at least a day at Queen Square. He was strongly supportive of autonomic nonprofit charities. He was one of the patrons of the Autonomic Disorders Association Sarah Matheson Trust (now the Multiple System Atrophy Trust). He was a founder trustee of the Autonomic Charitable Trust (ACT), always with invaluable insight and advice. He provided a major donation to ACT in 2015 after the auction of the running shoes in which he broke the 4-minutemile record.

Sir Roger took particular pride in the achievements and continuing development of the people and the departments he was associated with, as he wrote in his autobiography, Twin Tracks, in 2014. The Autonomic Unit he started in 1975 had expanded substantially, from a few hundred patient episodes in the mid-1980s to over 3000 annually with its sister national autonomic referral centre, the Pickering Unit at St Mary's. The two autonomic units have had a huge impact on the recognition, investigation, diagnosis and treatment of various autonomic disorders, and on the creation of clinical autonomic scientists, autonomic biochemists, and specialised autonomic nursing staff. Sir Roger was especially
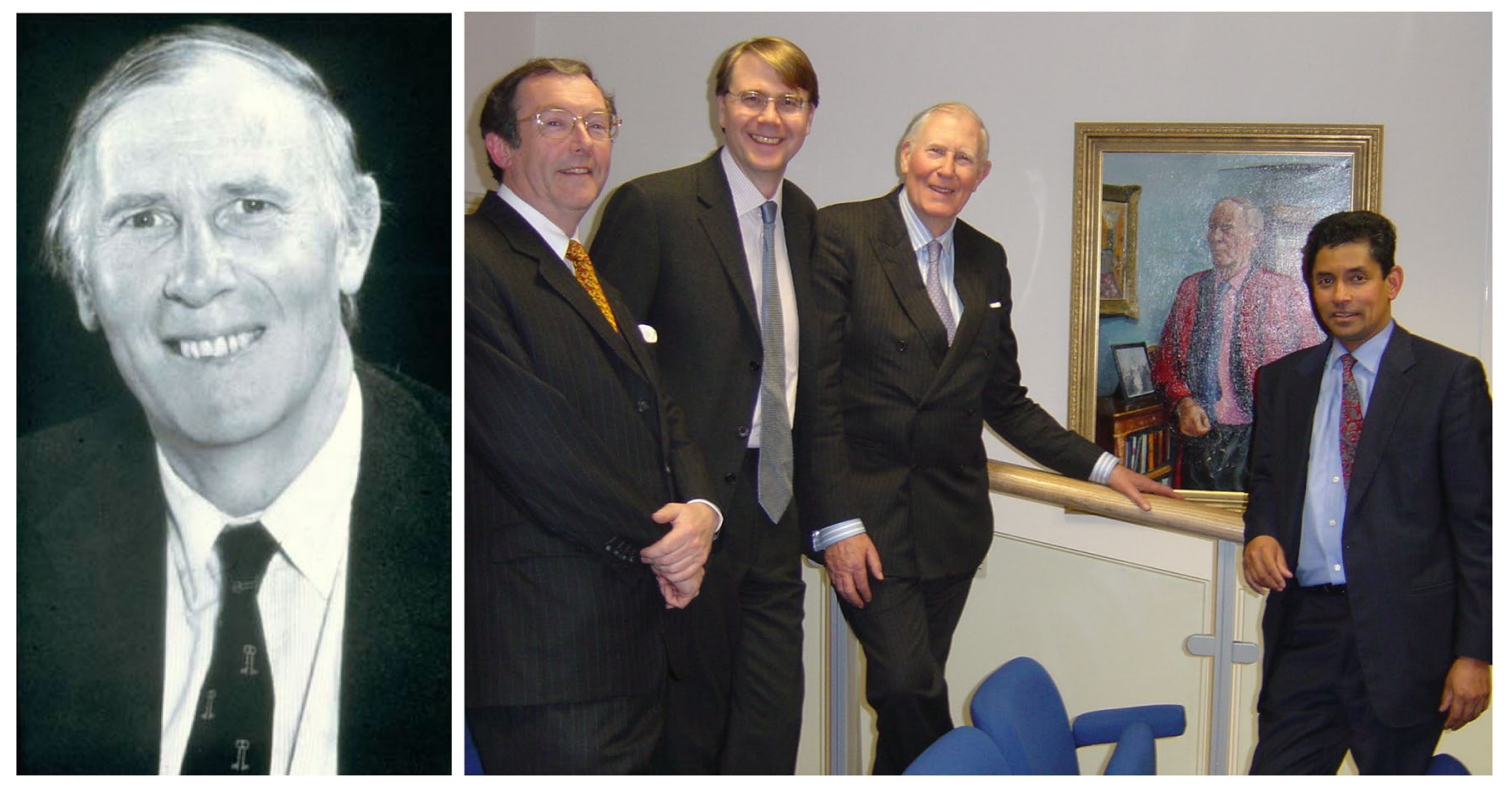

Fig. 1 Sir Roger Bannister (1929-2018). In the group photograph taken in 2004, Sir Roger (third left), is standing next to his portrait at the inauguration of the Bannister Lecture Theatre named in his honour at St Mary's Hospital, Imperial College London. On his right is his son Clive Bannister and Professor Dafydd Thomas, Consultant Neurologist at St Mary's Hospital. On his left is Professor Christopher Mathias 
proud of the role of the Autonomic Unit as a leader in teaching and training, with research fellows from all over the world, some now heading autonomic or allied departments in Great Britain and globally. The St Mary's and Queen Square Units amalgamated in 2014 to form a single autonomic unit at Queen Square, which is the National Health Service Referral Centre for autonomic disorders serving the entire UK. It is now an established department, with a Chair in Autonomic Neurology at the University College London Institute of Neurology, one of the world's largest neuroscience departments.

I was incredibly fortunate in having Sir Roger as a mentor, collaborator, friend and confidant. Moyra, Lady Bannister, has always been most supportive, and this enabled him to give us so much of his time, even when he was particularly busy. We were especially pleased that HM The Queen appointed him a member of the Order of the Companions of Honour in 2017. All of us in the field of autonomic medicine, and also patients with autonomic disorders, have been most privileged that he was a pioneer in, and remained totally committed and dedicated to, the autonomic field over so many decades.

Funding None.

\section{Compliance with ethical standards}

Conflict of interest The author declares that he has no conflict of interest.

\section{References}

1. Litsky F, Weber B (2018) Roger Bannister, first athlete to break the 4-minute mile, dies at 88. The New York Times. https://www. nytimes.com/2018/03/04/obituaries/roger-bannister-dead.html. Accessed 16 Jul 2018

2. Mason N, Richmond C (2018) Sir Roger Bannister obituary. The Guardian. https://www.theguardian.com/sport/2018/mar/04/sirroger-bannister-obituary. Accessed $16 \mathrm{Jul} 2018$

3. Bannister RG, Cunningham DJ, Douglas CG (1954) The carbon dioxide stimulus to breathing in severe exercise. J Physiol 125:90-117
4. Bannister RG, Cunningham DJ (1954) The effects on the respiration and performance during exercise of adding oxygen to the inspired air. J Physiol 125:118-137

5. Bannister R (1959) Acute anhidrotic heat exhaustion. Lancet $2: 313-316$

6. Bannister R, Ardill L, Fentem P (1967) Defective autonomic control of blood vessels in idiopathic orthostatic hypotension. Brain 90:725-746

7. Bannister R, Ardill L, Fentem P (1969) An assessment of various methods of treatment of idiopathic orthostatic hypotension. Q J Med 38:377-395

8. Bannister R, Oppenheimer DR (1972) Degenerative diseases of the nervous system associated with autonomic failure. Brain 95:457-474

9. Bannister R, Sever P, Gross M (1977) Cardiovascular reflexes and biochemical responses in progressive autonomic failure. Brain 100(2):327-344

10. Bannister R, Davies B, Holly E, Rosenthal T, Sever P (1979) Defective cardiovascular reflexes and supersensitivity to sympathomimetic drugs in autonomic failure. Brain 102:163-176

11. Spokes EG, Bannister R, Oppenheimer DR (1979) Multiple system atrophy with autonomic failure: clinical, histological and neurochemical observations on four cases. J Neurol Sci 43:59-82

12. da Costa DF, Bannister R, Landon J, Mathias CJ (1984) Growth hormone response to clonidine is impaired in patients with central sympathetic degeneration. Clin Exp Hypertens A 6(10-11):1843-1846

13. Mathias CJ, Fosbraey P, da Costa DF, Thornley A, Bannister R (1986) The effect of desmopressin on nocturnal polyuria, overnight weight loss, and morning postural hypotension in patients with autonomic failure. British Medical Journal (Clin Res Ed). 293(6543):353-354

14. Mathias CJ, da Costa DF, Fosbraey P, Bannister R, Wood SM, Bloom SR, et al. (1989) Cardiovascular, biochemical and hormonal changes during food-induced hypotension in chronic autonomic failure. J Neurol Sci 94(1-3):255-269

15. Smith GD, Bannister R, Mathias CJ (1993) Post-exertion dizziness as the sole presenting symptom of autonomic failure. Heart 69:359-361

16. Mathias CJ, Bannister RB, Cortelli P, Heslop K, Polak JM, Raimbach $S$ et al (1990) Clinical, autonomic and therapeutic observations in two siblings with postural hypotension and sympathetic failure due to an inability to synthesize noradrenaline from dopamine because of a deficiency of dopamine $\beta$ hydroxylase. Q J Med 75(278):617-633

17. Kaufmann H, Freeman R, Biagionni I, Low P, Pedder S, Hewitt LA, Mauney J, Feirtag M, Mathias CJ (2014) Droxidopa for neurogenic hypotension. A randomised, placebo controlled, phase 3 trial. Neurology 83:328-335

18. Mathias CJ, Bannister R (eds) (2013) Autonomic failure: a textbook of clinical disorders of the autonomic nervous system, 5th edn. Oxford University Press, Oxford (ISBN 978-0- 19-856634-2) 